\title{
Performance of surfactant blend formulations for controlling gas mobility and foam propagation under reservoir conditions
}

\author{
Muhammad Khan Memon $^{1} \cdot$ Khaled Abdalla Elraies $^{1} \cdot$ Mohammed Idrees Ali Al-Mossawy $^{1}$
}

Received: 17 April 2020 / Accepted: 27 August 2020 / Published online: 8 September 2020

(c) The Author(s) 2020

\begin{abstract}
The use of surfactant is one of the possible solutions to minimize the mobility of gases and improve the sweep efficiency, but the main problem with this process is its stability in the presence of injection water and crude oil under reservoir conditions. In this study, the three types of surfactant anionic, nonionic and amphoteric are examined in the presence of brine salinity at $96{ }^{\circ} \mathrm{C}$ and 1400 psia. To access the potential blended surfactant solutions as gas mobility control, laboratory test including aqueous stability, interfacial tension (IFT) and mobility reduction factor (MRF) were performed. The purpose of MRF is to evaluate the blocking effect of selected optimum surfactant solutions. Based on experimental results, no precipitation was observed by testing the surfactant solutions at reservoir temperature of $96^{\circ} \mathrm{C}$. The tested surfactant solutions reduced the IFT between crude oil and brine. The effectiveness and strength of surfactant solutions without crude oil under reservoir conditions were evaluated. A high value of differential pressure demonstrates that the strong foam was generated inside a core that resulted in delay in breakthrough time and reduction in the gas mobility. High mobility reduction factor result was measured by the solution of blended surfactant $0.6 \% \mathrm{AOS}+0.6 \% \mathrm{CA} 406 \mathrm{H}$. Mobility reduction factor of other tested surfactant solutions was found low due to less generated foam by using $\mathrm{CO}_{2}$ under reservoir conditions. The result of these tested surfactant solutions can provide the better understanding of the mechanisms behind generated foam stability and guideline for their implementation as gas mobility control during the process of surfactant alternating gas injection.
\end{abstract}

Keywords Foam $\cdot$ Foam quality $\cdot$ Gas mobility $\cdot$ Reservoir condition $\cdot$ Surfactant alternating gas

\section{Introduction}

The foam generated by the surfactants has been used in the enhanced oil recovery (EOR) as a gas mobility control. Injection of foam with gas overcomes the problems of viscous fingering, gas channeling and reservoir heterogeneity (Farnazeh and Sohrabi 2013; Green 1998). Trapping of large gas fraction in the reservoir and improving the apparent gas viscosity can significantly reduce the gas mobility (Bernard and Jacobs 1965). The generated foam by different types of surfactants was used in the recent years with several field trials including the flooding of steam foam (Patzek 1996), gas injection alternating with water assisted by foam (Blaker et al. 2002), $\mathrm{CO}_{2}$ foam flood

Muhammad Khan Memon

mkmemon@hotmail.com

1 Petroleum Engineering Department, Universiti Teknologi PETRONAS, Bandar Seri Iskandar, 32610 Tronoh, Perak Darul Ridzuan, Malaysia
(Chou et al. 1992), the foam generated by $\mathrm{CO}_{2}$ soluble surfactants (Mukherjee et al. 2016), in the fractured fluids (Blauer and Kohlhaas 1974; Wheeler 2010), in the shallow subsurface environmental remediation (Hirasaki et al. 1997; Mamun et al. 2002; Hirasaki 1989), and finally, in the tertiary oil recovery methods to switch the mobility of gas and overcome in situ permeability variations (Blaker et al. 2002). Anionic surfactants such as alpha olefin surfactant ( $\left.\mathrm{AOSc}_{14-16}\right)$ are mainly used in the EOR because of their excellent foam stability with a brine composition and tolerant to the presence of crude oil (Cubillos et al. 2012). Sodium dodecyl sulfate (SDS) is an anionic surfactant and used in many cleaning and hygiene products. Ammonium lauryl sulfate or alkyl ethoxy sulfate (STEOL CS-460) is an anionic surfactant with an excellent foaming and foam stability properties. This type of surfactant provides the excellent base for foaming and excellent foaming properties in hard and soft water. Ammonium alcohol ether sulfate (STEPSOL CA-406H) or alcohol ethoxy sulfate (AES) is an anionic surfactant having good foaming properties. 
Internal olefin sulfonate (IOS $\mathrm{C15-C18}$ ) can be used up to $200{ }^{\circ} \mathrm{C}$ but has a limited divalent ion tolerance. Alcohol alkoxy sulfate/alkyl ether sulfate (AAS) is used as an additive. This additive has an excellent divalent ion tolerance. Blend with AAS surfactant can improve the salt tolerance (Chemicals 2012). Nonionic surfactants are more tolerant to high salinity, but cannot significantly reduce the interfacial tension (IFT) as compared to the anionic surfactants. Amphoteric surfactants are known as zwitterionic surfactants, are expensive and temperature/brine salinity tolerant. Lauramidopropyl amine oxide (LMDO) is an example. This type of surfactant is used for foam enhancement and viscosity building. Amine oxide can be used as co-solvent with primary surfactant as mixed micelle for EOR. Amine oxides are salt tolerant that reduces the IFT and can develop viscosity. It can be used with anionic, nonionic and cationic surfactants. Sheng et al. (2020) investigated the IFT of anionic-nonionic surfactants and their blended solutions. The experimental result showed that the ethylene oxide (EO) group plays a vital role in the reducing IFT. The hydrophilic-lipophilic balance (HLB) was considered another important factor for reducing the IFT values (Sheng et al. 2020).

The foam can be generated into the reservoir by simultaneous injection of gas and surfactant solutions or alternating injection of gas and surfactant solutions ( $\mathrm{Xu}$ and Rossen 2003). Surfactant alternating gas (SAG) injection process has several advantages over simultaneous water alternating gas (SWAG) injection process. It minimizes gas-water contact in the surface installations and pipelines, which can be important in the presence of carbon dioxide (Donaldson et al. 1989; Heller 1994; Shi and Rossen 1998). Small slugs of SAG injection can promote foaming in the area near the well bore (Rossen and Gauglitz 1990). The main function of foam injection in the porous media is to control the movement of injected fluids throughout the reservoir with uniform flow. Surfactant concentration and injection velocity are important to control the resistance and the propagation of foam under the field conditions. Foam generated by low surfactant concentration is less stable. Using high surfactant concentration resulted in an increase in apparent viscosity, and improve the sweep efficiency. Understanding of laboratory experiments is considered as important parameter. These studies suggested that all related surfactant parameters must be analyzed before implementing in the field of EOR (Farnazeh and Sohrabi 2013; Al-Mossawy et al. 2011; Talebian et al. 2014). In the field of EOR, three main categories of foam are used.

1. Pre-formed foam The pre-formed foam improves higher resistance factor and blocks the porous medium.

2. Co-injection foam Co-injection of gas and surfactant solution.
3. Surfactant alternating gas (SAG) foam In this injection process, the gas and surfactant solution are injected alternatively. The SAG injection process can be profitable over the co-injection because of easier foam generation. This type of foam cannot block the porous medium completely (Turta and Singhal 1998; Smith 1988; Hanssen et al. 1994).

Chang et al. (1994) studied the effects of flow and quality of generated foam. They observed that the mobility of the foam was decreased with increasing flow rate (Chang et al. 1994). The foam generated from the surfactant was first offered by Holbrook for the purpose of controlling gas mobility (Boud and Holbrook 1958). Wang et al. (2017) performed laboratory experiments on four surfactants named nonionic surfactant nonylphenol polyethoxylate (NP), alkyl poly glycoside (APG-1214), anionic surfactant SDS and sodium dodecyl benzene sulfonate (SDBS) for their stability and half-lifetime. They concluded that good performance in the foam stability was obtained by nonionic surfactant (APG-1214) as compared to the other tested surfactants in their study. Further, they used core flood experiments for measuring the resistance factor. Surfactant (AP-1214) resulted in good synergistic when blended with another anionic surfactants (Wang et al. 2017).

Norouzi et al. (2018) studied the potential of foam on oil recovery. The foam propagation and potential of oil recovery by SDS and AOS were performed in the laboratory under pressure of $2000 \mathrm{psia}$ and $65^{\circ} \mathrm{C}$. After water flooding, the co-injection of nitrogen gas $\left(\mathrm{N}_{2}\right)$ and SDS was continued with the injection rate of $6 \mathrm{~cm}^{3} /$ hour. Similarly, in the second experiment, $\mathrm{N}_{2}$ gas and AOS were injected alternately with the same injection rate. The maximum foam stability was obtained from both types of surfactant solution. The generated foam stability by SDS resulted in a more stable than generated foam by AOS (Norouzi et al. 2018). Zhang et al. (2020) investigated the amine surfactants for smart mobility control during the $\mathrm{CO}_{2}$ flooding. They concluded in their experimental results that the tested amine surfactants performed better $\mathrm{CO}_{2}$ foaming ability under high temperature and high pressure (Zhang et al. 2020). It is clear from the previous studies, lot of research have been performed on foam stability, which was generated by different types of surfactants followed by $\mathrm{CO}_{2}$ injection. The generated foam acts as gas mobility control that results in improving the overall sweep efficiency. Most of the laboratory experiments were performed on different types of individual and blended surfactant solutions with low to high concentration. The focus was given on performed testing in terms of their generated foam stability, longevity and other parameters that effect the generated foam stability (Farzaneh and Sohrabi 2015; Simjoo et al. 2013; Memon et al. 2016). Extensive laboratory work has been done to study the performance 
Table 1 List of surfactants used in the experiments

\begin{tabular}{|c|c|c|c|c|}
\hline S. no. & Chemical name & Chemical description & Surfactant type & Active percent \\
\hline 1 & $\begin{array}{l}\text { BIO-TERGE } \\
\text { AS-40 } \\
\text { AOS }_{\mathrm{C} 14-16}\end{array}$ & Alpha Olefin sulfonate & Anionic & 39 \\
\hline 2 & STEPSOL CA-406H & Ammonium alcohol ether sulfate & Anionic & 60 \\
\hline 3 & $\begin{array}{l}\text { ENORDET } 0332 \\
\left(\mathrm{IOS}_{\mathrm{C} 15-18}\right)\end{array}$ & Internal olefin sulfonate & Anionic & 33.4 \\
\hline 4 & SDS & Sodium dodecyl sulfate (solid) & Anionic & 100 \\
\hline 5 & Triton TX-100 & Octylphenol ethylene oxide & Nonionic & 100 \\
\hline 6 & $\begin{array}{l}\text { ENORDET J771 } \\
\text { (AAS) }\end{array}$ & Alcohol alkoxy sulfate/alkyl ether sulfate & Additive & 26.2 \\
\hline 7 & STEOL CS-460 & Sodium lauryl sulfate, 3 MolesEO & Secondary Surfactant & 59 \\
\hline 8 & $\begin{array}{l}\text { AMMONYX } \\
\text { LMDO }\end{array}$ & Lauryl amido propyl amine oxide & Amphoteric & 33 \\
\hline
\end{tabular}

of foam in the conventional and unconventional reservoirs (Szlendak et al. 2013; Yang et al. 2019; Das et al. 2016). However, the selection of surfactant under particular reservoir condition is important. In this research study, the experiments have been accomplished in order to examine the mechanism of foam generated by using single and solution of blended surfactants under reservoir conditions. The purpose is to check the effectiveness and strength of optimum surfactant solutions without crude oil under reservoir conditions and the flowing behavior of different surfactant blended solutions with different concentrations through porous media. The blocking effect by surfactants on porous media was investigated. Foam generated from surfactants, either single or blended solutions, improved the volumetric sweep efficiency, reduced the gas mobility that resulted in a favorable mobility ratio. The findings of this research study on blended surfactants are favorable for gas mobility control during the SAG applications.

\section{Materials}

\section{Surfactants}

In the experiment, surfactants were used as received without further treatment. For the preparation of stock solution, 5\% of each surfactant was used in distilled water. From prepared stock solution, required concentration of each surfactant solution was mixed with prepared injection water. Table 1 shows the list of commercial surfactants used in this study.

\section{Synthetic brine (injection water)}

Injection water is prepared in the laboratory according to the field formation water. Table 2 shows the salts used in the injection water.
Table 2 Salts used in the prepared injection water

\begin{tabular}{lc}
\hline Salt & $\mathrm{g} / \mathrm{l}$ \\
\hline $\mathrm{NaCl}$ & 23.6 \\
$\mathrm{CaCl}_{2} \cdot 2 \mathrm{H}_{2} \mathrm{O}$ & 1.3 \\
$\mathrm{MgCl}_{2} \cdot 6 \mathrm{H}_{2} \mathrm{O}$ & 10.20 \\
$\mathrm{KCl}$ & 0.62 \\
$\mathrm{NaHCO}_{3}$ & 0.225 \\
$\mathrm{Na}_{2} \mathrm{SO}_{4}$ & 3.9 \\
\hline
\end{tabular}

Table 3 Crude oil properties

\begin{tabular}{ll}
\hline Oil type & Waxy crude oil \\
\hline Viscosity $(\mathrm{Cp}) 96{ }^{\circ} \mathrm{C}, 1400 \mathrm{psia}$ & 1.5 \\
Density $\left(\mathrm{g} / \mathrm{cm}^{3}\right) 96{ }^{\circ} \mathrm{C}, 1400 \mathrm{psia}$ & 0.7886 \\
${ }^{0} \mathrm{API}$ & 37.7 \\
Wax content (\%) & 26.7 \\
Saturates $(\%)$ & 82.15 \\
Aromatics $(\%)$ & 15.4 \\
Resins (\%) & 2.26 \\
Asphaltenes (\%) & 0.18 \\
\hline
\end{tabular}

\section{Crude oil}

Malaysian crude oil was used for this research study. The properties of this crude oil are shown in Table 3.

\section{$\mathrm{CO}_{2}$ gas}

$\mathrm{CO}_{2}$ gas with purity of $99.9 \%$ was used in the core flood experiment under $1400 \mathrm{psia}$ and $96{ }^{\circ} \mathrm{C}$. Table 4 shows the properties of pure $\mathrm{CO}_{2}$ gas. 
Table 4 Properties of $\mathrm{CO}_{2}$ gas

\begin{tabular}{ll}
\hline Properties & Result \\
\hline Apparent molecular weight $(\mathrm{g} / \mathrm{mol})$ & 44 \\
Density of $\mathrm{CO}_{2}\left(\mathrm{~g} / \mathrm{cm}^{3}\right)$ & 0.1854 \\
Viscosity of $\mathrm{CO}_{2}(\mathrm{cp})$ & 0.0184 \\
Critical temperature $\left({ }^{\circ} \mathrm{C}\right)$ & 31.1 \\
Critical pressure (psia) & 1070 \\
\hline
\end{tabular}

Table 5 Chemical composition of Berea sandstone

\begin{tabular}{lc}
\hline Chemical composition & Percentage $(\%)$ \\
\hline Silica $\left(\mathrm{SiO}_{2}\right)$ & 93.13 \\
Alumina $\left(\mathrm{Al}_{2} \mathrm{O}_{3}\right)$ & 3.86 \\
Magnesium oxide $(\mathrm{MgO})$ & 0.25 \\
Ferric oxide $\left(\mathrm{Fe}_{2} \mathrm{O}_{3}\right)$ & 0.11 \\
Ferrous oxide $(\mathrm{FeO})$ & 0.54 \\
Calcium oxide $(\mathrm{CaO})$ & 0.10 \\
\hline
\end{tabular}

Figure 1 shows the experiment performed on SV T20 spinning drop tensiometer. The cleaned capillary tube is filled with the surfactant-containing brine solution. After that, the drop of crude oil is injected inside the capillary tube by using syringe. The injected drop size was observed as three times greater in diameter than minor diameter drop. This is compulsory for accurate IFT measurements. The rotating speed of capillary tube was steadily increased in order to elongate the oil drop and to make it an elliptical shape. After attainment of the elliptical shape of oil drop, a dimensional profile was extracted and then hold down to initiate the IFT measurement.

\section{Core flood experiment}

Core flood equipment was used for SAG experiments. The schematic flow diagram of fluid displacement process during the experiment is shown in Fig. 2. The core flood equipment consists of a core holder, ISCO syringe type pumps for controlling the confining and back pressure during the
Table 6 Berea sandstone core properties

\begin{tabular}{lllllll}
\hline Sample ID & Diameter $(\mathrm{cm})$ & Length $(\mathrm{cm})$ & $\begin{array}{l}\text { Pore vol- } \\
\text { ume }\left(\mathrm{cm}^{3}\right)\end{array}$ & $\begin{array}{l}\text { Bulk vol- } \\
\text { ume }\left(\mathrm{cm}^{3}\right)\end{array}$ & Porosity $(\%)$ & $\begin{array}{l}\text { Liquid } \\
\text { permeability } \\
(\mathrm{mD})\end{array}$ \\
\hline M1 & 3.827 & 7.658 & 18.46 & 88.04 & 20.9 & 153.5 \\
M2 & 3.860 & 7.625 & 17.49 & 89.18 & 19.6 & 153.5 \\
M3 & 3.855 & 7.632 & 17.42 & 89.03 & 19.57 & 172 \\
M4 & 3.863 & 7.663 & 17.54 & 89.76 & 19.54 & 145.2 \\
M5 & 3.830 & 7.668 & 17.70 & 88.29 & 20 & 164 \\
M6 & 3.853 & 7.653 & 18.17 & 89.18 & 20.37 & 149 \\
\hline
\end{tabular}

\section{Berea sandstone}

Table 5 shows the chemical composition of Berea core samples and Table 6 shows the Berea sandstone core properties (Berea sandstone 2014). The digital caliper was used to measure the length and diameter of core samples and the measurement was taken accurately on the LCD screen.

\section{Methodology}

\section{Interfacial tension}

A spinning drop tensiometer (Model SV T20) was used to measure the IFT values of crude oil/brine water and crude oil/surfactant solutions at atmospheric pressure and constant temperature of $85{ }^{\circ} \mathrm{C}$. Temperature $85{ }^{\circ} \mathrm{C}$ was used due to the transparent visualization of crude oil drop in the capillary tube. At $96{ }^{\circ} \mathrm{C}$, oil drop cannot be seen due to the creation of vapors in aqueous mixed surfactant solution.

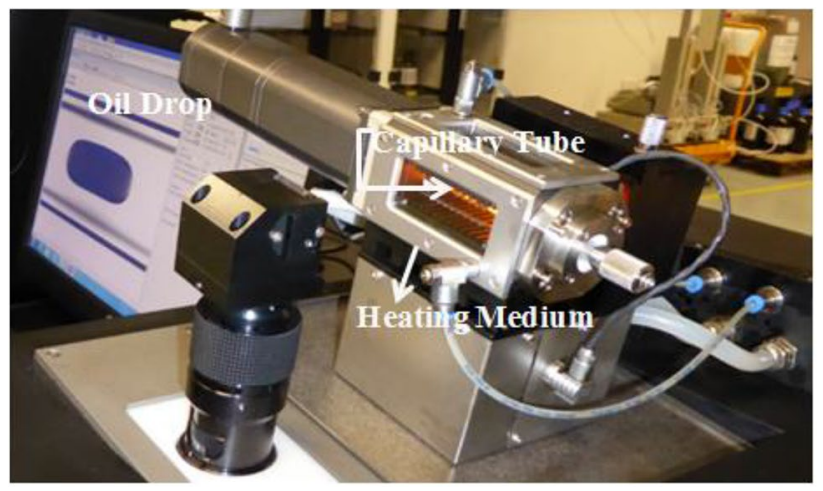

Fig. 1 Elliptical shape of oil drop during experiment by SV T20 spinning drop tensiometer

fluid displacement process. The pump was connected with three stainless steel accumulators, where the test fluid can be stored and circulate to the core. All operating valves, piping 
Fig. 2 Schematic diagram of SAG flooding

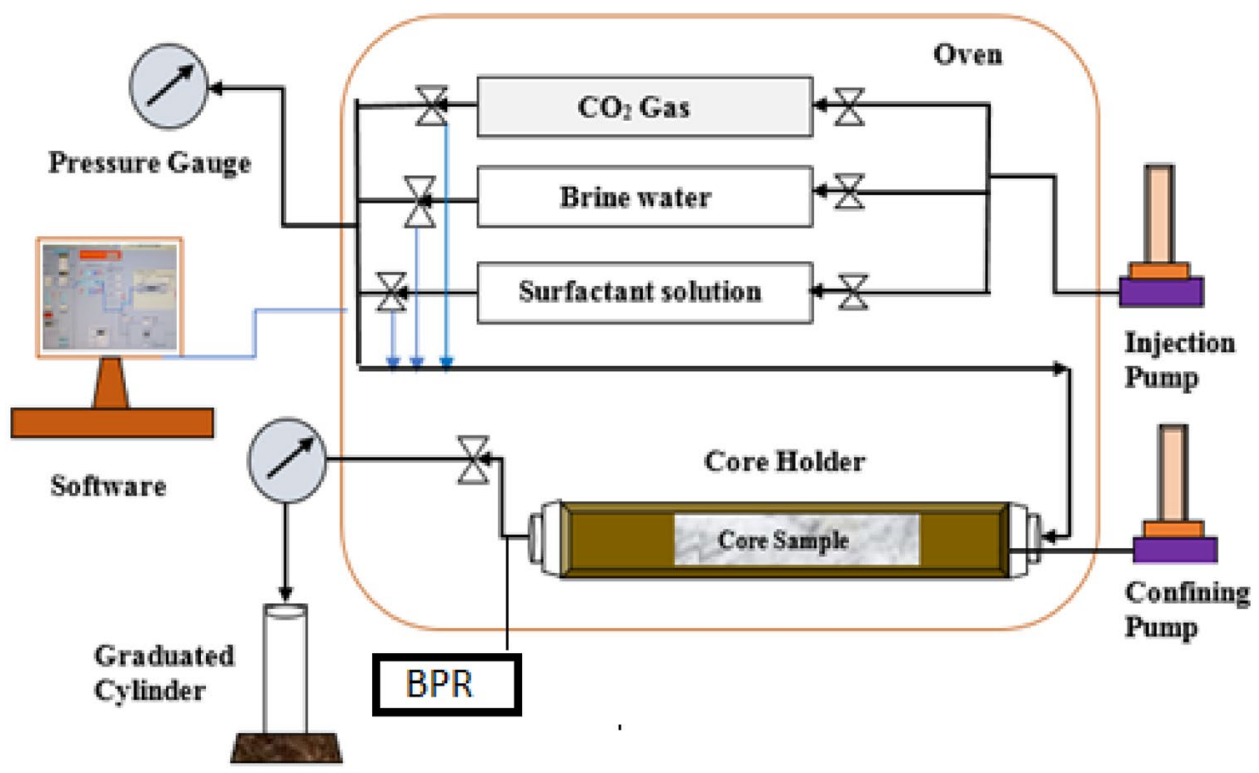

and transmitters are made in acid-resistant material to protect the corrosion. For each experiment test, a separate Berea sandstone core sample was used. The core samples were vacuumed and saturated with brine water for 3 days. The core was placed in the Hassler core holder horizontally. Air was used as confining fluid. The back pressure regulator (BPR) is connected to exit of core that was also controlled by the pump. The brine water, $\mathrm{CO}_{2}$ and surfactant solutions were transferred into the three accumulators that were set in the oven. Core holder was set in an oven under test temperature of $96^{\circ} \mathrm{C}$ and back pressure of 1400 psia. The confining pressure was set at $1900 \mathrm{psia}$. The injection water was injected with fixed rate of $0.50 \mathrm{~cm}^{3} / \mathrm{min}$. After that, the prepared optimum solution of blended surfactant was injected before and after injection of $\mathrm{CO}_{2}$ slug with the same injection rate. Each fluid was injected until the steady-state condition. The fluid (effluent) was collected in the graduate glass cylinder.

\section{Results and discussion}

The aqueous stability of selected surfactant solutions in the presence of brine salinity was evaluated at $96^{\circ} \mathrm{C}$. The compatibility of these surfactants is monitored over time up to 4 weeks by observing the aqueous stability in terms of no phase separation, clouds and precipitation.

The MRF is calculated through the differential pressure profile by using the core flood experiments described in the previous published work (Memon et al. 2016). It was concluded in our published work that the blended surfactant solution with equal concentration of $0.6 \mathrm{wt} \% \mathrm{AOS}+0.6 \mathrm{wt} \% \mathrm{TX} 100$ and $0.6 \mathrm{wt} \% \mathrm{AOS}+0.6 \mathrm{wt} \% \mathrm{LMDO}$ performed better under reservoir conditions as compared to the single surfactant solution of $0.6 \mathrm{wt} \% \mathrm{AOS}$. In this study, further six surfactant solutions were tested for gas mobility control at the fixed injection rate under the same reservoir conditions $\left(96{ }^{\circ} \mathrm{C}\right.$ and $1400 \mathrm{psia})$.

\section{Interfacial tension}

The IFT values between crude oil/brine water are measured with tensiometer at $85^{\circ} \mathrm{C}$ resulted in $12 \mathrm{mN} / \mathrm{m}$. The IFT values between crude oil/surfactant solutions are reduced from 12 to $1.85 \mathrm{mN} / \mathrm{m}$. Table 7 shows the measured IFT values of all surfactant solutions. Low IFT values were achieved by using blend of surfactants with different concentrations. The reduction of IFT values from all different concentrations is due to the surfactant molecules adsorbed at the interface and provided the expanding force acting against the normal IFT. Therefore, all concentrations of $\mathrm{AOS}_{\mathrm{C} 14-16}$ and its blend moved to the lower IFT. The IFT between surfactant SDS/ oil and its blend with other surfactant solution was tested with crude oil. The same trend of reduction in IFT was obtained with increase in the concentrations of surfactants.

Table 7 Interfacial tension of tested surfactant solution

\begin{tabular}{lll}
\hline Core ID & Formulations & IFT $(\mathrm{mN} / \mathrm{m})$ \\
\hline M1 & 0.2\%AOS +0.2\%TX-100/oil & 0.92 \\
M2 & $0.6 \% \mathrm{AOS}+0.6 \% \mathrm{CS} 460 /$ oil & 1.32 \\
M3 & $0.6 \% \mathrm{AOS}+0.6 \% \mathrm{CA} 406 \mathrm{H} / \mathrm{oil}$ & 1.85 \\
M4 & $0.2 \% \mathrm{SDS}+0.2 \% \mathrm{TX}-100 /$ oil & 1.5 \\
M5 & $0.4 \% \mathrm{SDS}+0.4 \% \mathrm{AAS} / \mathrm{oil}$ & 1.15 \\
M6 & $0.4 \% \mathrm{IOS}_{\mathrm{C} 15-18} / \mathrm{oil}$ & 0.134 \\
\hline
\end{tabular}


An increase in IFT value was observed by surfactant blend of $0.6 \% \mathrm{AOS}+0.6 \% \mathrm{CA} 406 \mathrm{H} / \mathrm{oil}$ as compared to the other surfactant solutions. The general trend is that IFT value is decreased with increasing of surfactant concentrations. The increase in IFT value is due to high dissimilarity into two phases at the interface, or due to the Gibbs-Marangoni elasticity effect. As the film stretches under an applied stress, the area was increased and amount of surfactant adsorbed at the gas/liquid surfaces. Gibbs elasticity increases with an increase in surfactant concentration (Acharya et al. 2005). Therefore, the tested surfactant solutions reduced the IFT between crude oil and brine. Low IFT is a result of strong interactions between surfactant and oil molecules.

\section{Mobility reduction factor}

Equation 1 is used for calculating the MRF values, which were suggested in the published papers (Hirasaki et al. 1997; Mannhardt et al. 2000; Schramm 1994; Rosman and Kam 2009). Mathematically:

$\mathrm{MRF}=\frac{\Delta p(\text { presence of surface } \tan t)}{\Delta p(\text { without surface } \tan t)}=\frac{\Delta p_{\text {Foam }}}{\Delta p_{\text {no Foam }}}$.

The generated foam by the surfactant solution M1 $(0.2 \% \mathrm{AOS}+0.2 \% \mathrm{TX} 100)$ with equal concentration in the presence of $\mathrm{CO}_{2}$ at 1400 psia and $96{ }^{\circ} \mathrm{C}$ is shown in Fig. 3 . An increase in the pressure was detected when another slug of $\mathrm{CO}_{2}$ was injected after the injection of surfactant solution. In this displacement process, less foam was generated inside a core sample to control the gas mobility. The use of low concentration of this surfactant blend showed small values of MRF. The blended surfactant solution $0.6 \mathrm{wt} \%$ AOS + $0.6 \mathrm{wt} \%$ TX100 used in the previous study showed good reduction in the gas mobility due to the stable foam inside a core (Memon et al. 2016). Therefore, the maximum foam stability can provide better reduction in the

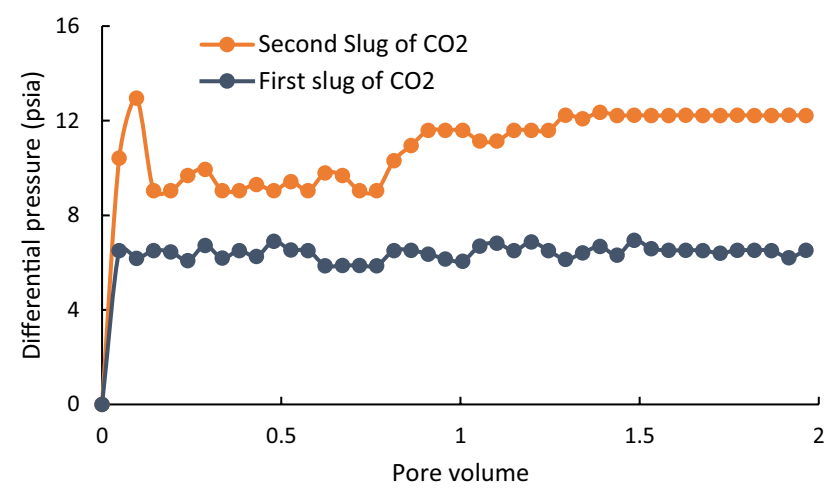

Fig. 3 Performance of injected $\mathrm{CO}_{2}$ slug before and after blended surfactant solution of $0.2 \% \mathrm{AOS}+0.2 \% \mathrm{TX} 100$ gas mobility. Figure 4 shows the differential pressure and MRF of M2 (0.6\%AOS + 0.6\%CS460) core sample. Differential pressure profile showed that less foam was generated at the initial displacement of this surfactant blend. The strong foam was generated after injecting 1.7 pore volume of $\mathrm{CO}_{2}$ injection. Therefore, the generated foam by this type of surfactant blend is considered from weak to strong foam. The differential pressure of M3 $(0.6 \% \mathrm{AOS}+0.6 \% \mathrm{CA} 406 \mathrm{H})$ core sample is shown in Fig. 5. Same behavior in differential pressure was recorded as surfactant blend solution used in core M2. Constant MRF was not observed by this type of surfactant blend because differential pressure was not reached at steady-state conditions. At the first stage, after injected 1.15PV of $\mathrm{CO}_{2}$ differential pressure showed that rise in the MRF values. The differential pressure increased dramatically up to $80 \mathrm{psia}$. This increase in the differential pressure was due to the foam generated inside a core and maintained high apparent viscosity. The differential pressure starts to decline after 2.2PV gas injected. Small reduction in gas mobility was observed by this surfactant blend solution. The differential pressure of M4 (0.2\% SDS + 0.2\% TX-100) core sample versus pore volume is shown in Fig. 6. Same performance was observed during the displacement process

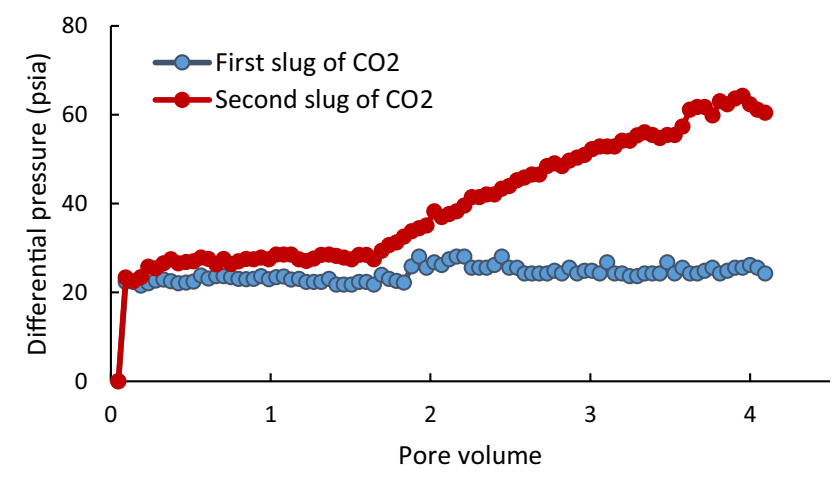

Fig. 4 Performance of injected $\mathrm{CO}_{2}$ slug before and after blended surfactant solution of $0.6 \% \mathrm{AOS}+0.6 \% \mathrm{CS} 460$

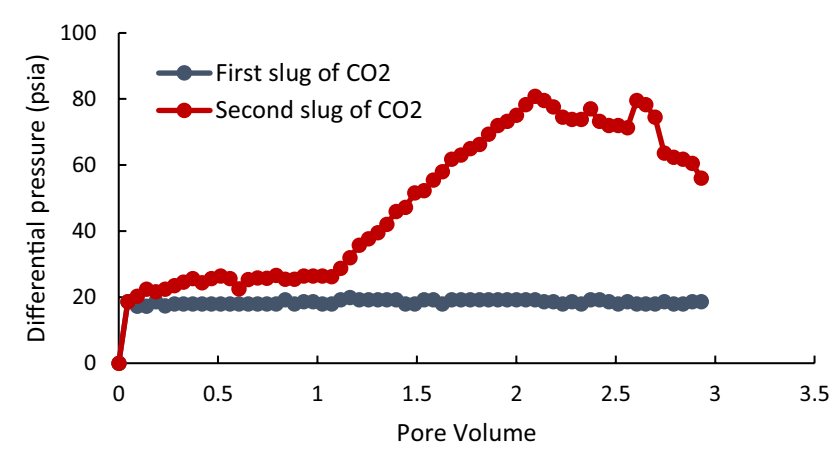

Fig. 5 Performance of injected $\mathrm{CO}_{2}$ slug before and after blended surfactant solution of $0.6 \% \mathrm{AOS}+0.6 \% \mathrm{CA} 406 \mathrm{H}$ 


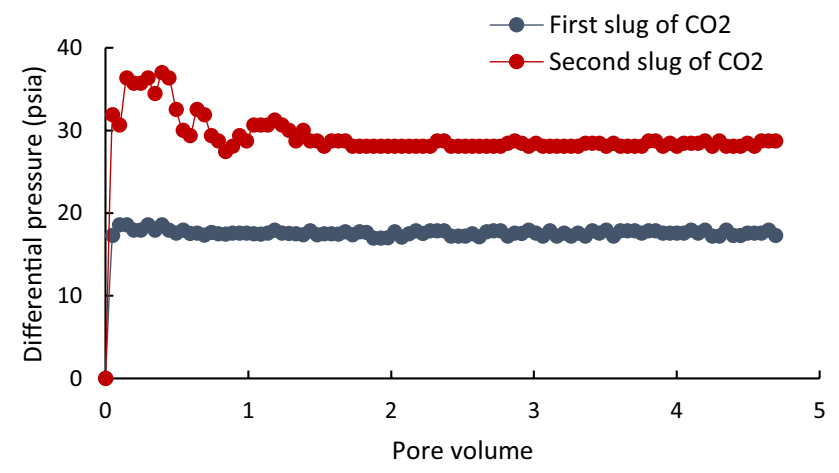

Fig. 6 Performance of injected $\mathrm{CO}_{2}$ slug before and after blended surfactant solution of $0.2 \% \mathrm{SDS}+0.2 \% \mathrm{TX} 100$

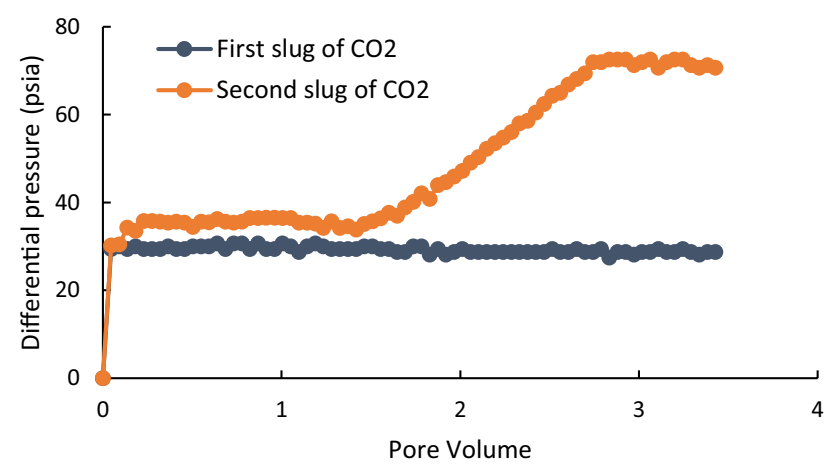

Fig. 7 Performance of injected $\mathrm{CO}_{2}$ slug before and after blended surfactant solution of $0.4 \% \mathrm{SDS}+0.4 \%$ AAS

as the surfactant blend $(0.2 \% \mathrm{AOS}+0.2 \% \mathrm{TX} 100)$ performed in the core sample M1. Less foam was generated inside a core sample by this surfactant blend solution to reduce the gas mobility. Figure 7 shows the differential pressure of M5 $(0.4 \%$ SDS + 0.4\% AAS $)$ core sample. Increase in pressure differential was observed continuously after injecting one pore volume (1PV). Addition of additives AAS to surfactant solution of SDS can produce the synergistic effect, that increase the stability of generated foam by improving the lamellae elasticity, strengthening the lamellae to decrease the gas diffusion, dropping the liquid drainage and increasing the viscosity of tested surfactant solution. The foam made by this blend of surfactant is considered more constant as compared to the blended surfactant solution of M4 $(0.2 \% \mathrm{SDS}+0.2 \% \mathrm{TX} 100)$. Figure 8 shows the differential pressure of M6 (0.4\% $\left.\mathrm{IOSc}_{15-18}\right)$ core sample. Weak foam was observed through pressure differential profile by this type of surfactant. The decline in the differential pressure showed early breakthrough, which resulted from the density and viscosity difference between the two injected fluids. The single surfactant with concentration of $0.4 \% \mathrm{IOSc}_{15-18}$ was generated less amount of foam and was less stable. The less foam stability by this surfactant $\operatorname{IOSc}_{15-18}$ was

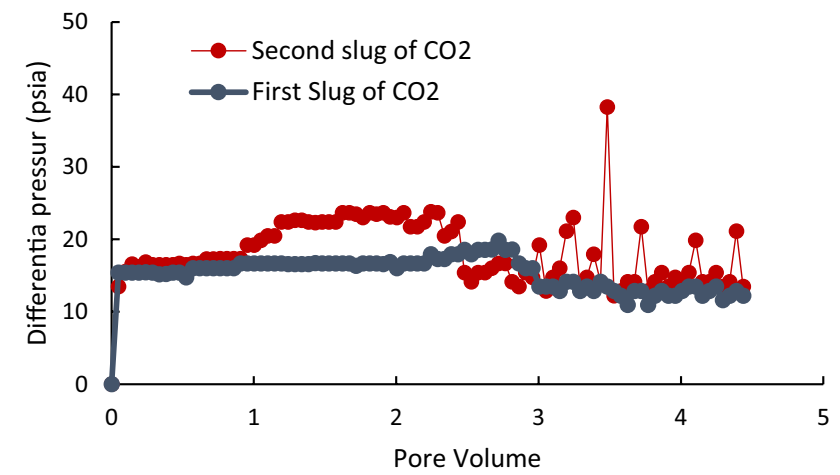

Fig. 8 Performance of injected $\mathrm{CO}_{2}$ slug before and after single surfactant of $0.4 \% \mathrm{IOSc}_{15-18}$

Table 8 MRF result of surfactant formulations at reservoir conditions

\begin{tabular}{lllll}
\hline Core ID & Formulations & $\Delta p_{\text {(no foam) }}$ & $\Delta p_{\text {(foam) }}$ & MRF \\
\hline M1 & $0.2 \% \mathrm{AOS}+0.2 \% \mathrm{TX}-100$ & 6.23 & 10.73 & 1.72 \\
M2 & $0.6 \% \mathrm{AOS}+0.6 \% \mathrm{CS} 460$ & 24.79 & 43.18 & 1.74 \\
M3 & $0.6 \% \mathrm{AOS}+0.6 \% \mathrm{CA} 406 \mathrm{H}$ & 18.48 & 43.8 & 2.37 \\
M4 & $0.2 \% \mathrm{SDS}+0.2 \% \mathrm{TX}-100$ & 20 & 29.15 & 1.46 \\
M5 & $0.4 \% \mathrm{SDS}+0.4 \% \mathrm{AAS}$ & 29.18 & 43.96 & 1.51 \\
M6 & $0.4 \% \mathrm{IOS}_{\mathrm{C} 15-18}$ & 15.4 & 17.13 & 1.11 \\
\hline
\end{tabular}

due to their large specific surface area per unit of molecules (Kumar and Mandal 2016, 2017). Due to the large size and nonionic nature of the $\operatorname{IOSc}_{15-18}$ surfactant head group, its Gibbs-Marangoni effect is weak. Consequently, more rapid degradation of the foam was observed. Also the performance of generated foam by using $\mathrm{CO}_{2}$ depends on the selected surfactant characteristics and required parameters such as injection water salinity, pressure and temperature. The density of $\mathrm{CO}_{2}$ increased under high pressure, while the impact of pressure on the density of water was negligible. Therefore, it was clear that the change in pressure can alter the hydrophobicity and hydrophilicity of the surfactant. The solubility of gas in water has a negative effect on the stability of the foam generated because it can accelerate the coalescence of the generated foam. Table 8 shows the differential pressure and MRF of evaluated individual and blended surfactants under reservoir conditions at fixed injection rate of $0.50 \mathrm{~cm}^{3} / \mathrm{min}$. The mobility reduction through core displacement experiment was the result of surfactant type, its concentration and injection rate. Generally, gas mobility was reduced when generated foam must be stable under the reservoir conditions. High MRF values were obtained by the solution of blended surfactant $0.6 \% \mathrm{AOS}+0.6 \% \mathrm{CA} 406 \mathrm{H}$. An increase in the MRF values by this blend surfactant showed that the generated foam was stable. The decline in the stability of generated foam due to the presence of

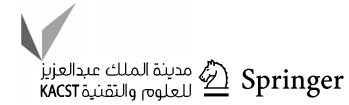


salinity, high temperature and other parameters has led to chemical modifications and formulations with the development of new technologies (Mannhardt et al. 2000; Zhu et al. 1998). Obtained MRF values larger than one indicated that the foam was generated inside a core. If the value of MRF is lower than one $(\mathrm{MRF}<1)$, this means that there is no foam generated inside the core. MRF range is considered as 1-10,000 (Sheng 2013), when foam becomes stable, more resistance to flow, that resulted in a higher mobility reduction. The MRF result showed that the blended surfactants exhibited better foam stability than the foam generated by using individual/single surfactant.

\section{Conclusions}

- The effectiveness and strength of a single surfactant and five blended surfactant solutions in the absence of oil under reservoir conditions were evaluated at fixed SAG injection rate.

- Surfactant $\mathrm{AOS}_{\mathrm{C} 14-16}$ was recognized as good foaming agent in SAG. Good stability was observed when $\mathrm{AOS}_{\mathrm{C} 14-16}$ was blended with other surfactant solutions. These blended surfactant solutions reduced the IFT between crude oil and brine.

- A high value of differential pressure indicated that the generation of strong foam inside a core resulted in delay in breakthrough time and reduction in the gas mobility.

- Maximum MRF result was obtained by a blend of surfactant solution $0.6 \% \mathrm{AOS}+0.6 \% \mathrm{CA} 406 \mathrm{H}$ at the reservoir pressure of 1400 psia and temperature $96{ }^{\circ} \mathrm{C}$.

- The solution of blended surfactants plays an imperative role in controlling the mobility of gas during the alternating injection of surfactant and gas.

Acknowledgements This research work was supported by Universiti Teknologi PETRONAS Malaysia during a full-time Ph.D. research candidate in the field of Petroleum Engineering. Thanks to STEPAN and SHELL Chemicals USA, who provided the surfactant samples.

Open Access This article is licensed under a Creative Commons Attribution 4.0 International License, which permits use, sharing, adaptation, distribution and reproduction in any medium or format, as long as you give appropriate credit to the original author(s) and the source, provide a link to the Creative Commons licence, and indicate if changes were made. The images or other third party material in this article are included in the article's Creative Commons licence, unless indicated otherwise in a credit line to the material. If material is not included in the article's Creative Commons licence and your intended use is not permitted by statutory regulation or exceeds the permitted use, you will need to obtain permission directly from the copyright holder. To view a copy of this licence, visit http://creativecommons.org/licenses/by/4.0/.

\section{References}

Acharya DP, Gutiérrez JM, Aramaki K, Aratani K-I, Kunieda H (2005) Interfacial properties and foam stability effect of novel geminitype surfactants in aqueous solutions. J Colloid Interface Sci 291:236-243

Al-Mossawy MI, Demiral B, Raja DA (2011) Foam dynamics in porous media and its applications in enhanced oil recovery: review. Universiti Teknologi PETRONAS, Kuala Lumpur

Bernard GG, Jacobs W (1965) Effect of foam on trapped gas saturation and on permeability of porous media to water. Soc Petrol Eng J 5:295-300

Blaker T, Aarra MG, Skauge A, Rasmussen L, Celius HK, Martinsen HA et al (2002) Foam for gas mobility control in the Snorre field: the FAWAG project. SPE Reserv Eval Eng 5:317-323

Blauer RE, Kohlhaas C (1974) Formation fracturing with foam. In: Fall meeting of the society of petroleum engineers of AIME

Boud DC, Holbrook OC (1958) Gas drive oil recovery process. Google Patents

Chang S-H, Martin F, Grigg R (1994) Effect of pressure on $\mathrm{CO}_{2}$ foam displacements: a micromodel visualization study. In: SPE/DOE improved oil recovery symposium

Chemicals S (2012) Surfactants, vol 2012. http://www.shell.com

Chou S, Vasicek S, Pisio D, Jasek D, Goodgame J (1992) $\mathrm{CO}_{2}$ foam field trial at north ward-estes. In: SPE annual technical conference and exhibition

Cubillos H, Montes J, Prieto C, Romero P (2012) Assessment of foam for GOR control to optimize miscible gas injection recovery. In: SPE improved oil recovery symposium

Das A, Nguyen N, Alkindi A, Farajzadeh R, Azri N, Southwick J et al (2016) Low tension gas process in high salinity and low permeability reservoirs. In: SPE EOR conference at oil and gas west Asia

Donaldson EC, Chilingarian GV, Yen TF (1989) Enhanced oil recovery, II: processes and operations. Elsevier, Amsterdam

Farnazeh S, Sohrabi M (2013) A review of the status of foam applications in enhanced oil recovery. In: Society of petroleum engineers. SPE-164917. Presentation at the EAGE annual conference and exhibition incorporating SPE Europe held in London

Farzaneh SA, Sohrabi M (2015) Experimental investigation of $\mathrm{CO}_{2}$-foam stability improvement by alkaline in the presence of crude oil. Chem Eng Res Des 94:375-389

Green DW (1998) Enhanced oil recovery. SPE Text book series, vol 6. Society of Petroleum Engineers

Hanssen J, Holt T, Surguchev L (1994) Foam processes: an assessment of their potential in North Sea reservoirs based on a critical evaluation of current field experience. In: SPE/DOE improved oil recovery symposium

Heller JP (1994) $\mathrm{CO}_{2}$ foams in enhanced oil recovery. ACS Publications, Washington

Hirasaki G (1989) A review of steam-foam process mechanisms. In: Paper SPE, vol 19518

Hirasaki G, Miller C, Szafranski R, Lawson J, Akiya N (1997) Surfactant/foam process for aquifer remediation. In: International symposium on oilfield chemistry

Kumar S, Mandal A (2016) Studies on interfacial behavior and wettability change phenomena by ionic and nonionic surfactants in presence of alkalis and salt for enhanced oil recovery. Appl Surf Sci 372:42-51

Kumar S, Mandal A (2017) Investigation on stabilization of $\mathrm{CO}_{2}$ foam by ionic and nonionic surfactants in presence of different additives for application in enhanced oil recovery. Appl Surf Sci 420:9-20

Mamun C, Rong J, Kam S, Liljestrand H, Rossen W (2002) Extending foam technology from improved oil recovery to environmental remediation. In: Paper SPE 77557 presented at the SPE annual technical conference exhibition, San Antonio, TX 
Mannhardt K, Novosad J, Schramm L (2000) Comparative evaluation of foam stability to oil. SPE Reserv Eval Eng 3:23-34

Memon MK, Shuker MT, Elraies KA (2016) Study of blended surfactants to generate stable foam in presence of crude oil for gas mobility control. J Pet Explor Prod Technol 7:77

Mukherjee J, Nguyen QP, Scherlin J, Vanderwal P, Rozowski P (2016) $\mathrm{CO}_{2}$ foam pilot in salt creek field, Natrona county, WY: phase III: analysis of pilot performance. In: SPE improved oil recovery conference

Norouzi H, Madhi M, Seyyedi M, Rezaee M (2018) Foam propagation and oil recovery potential at large distances from an injection well. Chem Eng Res Des 135:67-77

Patzek TW (1996) Field applications of steam foam for mobility improvement and profile control. SPE Reserv Eng 11:79-86

Rosman A, Kam S (2009) Modeling foam-diversion process using three-phase fractional flow analysis in a layered system. Energy Sour Part A 31:936-955

Rossen W, Gauglitz P (1990) Percolation theory of creation and mobilization of foams in porous media. AIChE J 36:1176-1188

Schramm LL (1994) Foam sensitivity to crude oil in porous media. ACS Adv Chem Ser 242:165-200

Sheng J (2013) Enhanced oil recovery field case studies. Gulf Professional Publishing, Houston

Sheng S-S, Cao X-L, Zhu Y-W, Jin Z-Q, Zhang L, Zhu Y et al. (2020) Structure-activity relationship of anionic-nonionic surfactant for reducing interfacial tension of crude oil. J Mol Liq 112772

Shi J, Rossen W (1998) Improved surfactant-alternating-gas foam process to control gravity override. In: SPE/DOE improved oil recovery symposium

Simjoo M, Dong Y, Andrianov A, Talanana M, Zitha PL (2013) Novel insight into foam mobility control. SPE J 18:416-427

Smith DH (1988) Surfactant-based mobility control. American Chemical Society, Washington

Szlendak SM, Nguyen NM, Nguyen QP (2013) Laboratory investigation of low-tension-gas flooding for improved oil recovery in tight formations. SPE J 18:851-866
Talebian SH, Masoudi R, Tan IM, Zitha PLJ (2014) Foam assisted $\mathrm{CO}_{2}$-EOR: a review of concept, challenges, and future prospects. J Petrol Sci Eng 120:202-215

Turta A, Singhal A (1998) Field foam applications in enhanced oil recovery projects: screening and design aspects. In: Paper SPE 48895 presented at the international conference and exhibition in China, Beijing, 2-6 November

Wang Y, Zhang Y, Liu Y, Zhang L, Ren S, Lu J et al (2017) The stability study of $\mathrm{CO}_{2}$ foams at high pressure and high temperature. $\mathrm{J}$ Petrol Sci Eng 154:234-243

Wheeler RS (2010) A study of high-quality foamed fracturing fluid properties. In: Canadian unconventional resources and international petroleum conference

Xu Q, Rossen W (2003) Experimental study of gas injection in surfactant-alternating-gas foam process. In: SPE annual technical conference and exhibition

Place M. Cleveland Berea sandstone (2014) USA. https://www.cleve landquarries.com

Yang J, Wang X, Peng X, Du Z, Zeng F (2019) Experimental studies on $\mathrm{CO}_{2}$ foam performance in the tight cores. J Petrol Sci Eng 175:1136-1149

Zhang P, Diao Y, Shan Y, Pei S, Ren S, Zhang L et al (2020) Experimental investigation of amine-surfactant $\mathrm{CO}_{2}$ foam for smart mobility control during $\mathrm{CO}_{2}$ flooding. J Petrol Sci Eng 184:106511

Zhu T, Strycker A, Raible C, Vineyard K (1998) Foams for mobility control and improved sweep efficiency in gas flooding. In: SPE/ DOE improved oil recovery symposium

Publisher's Note Springer Nature remains neutral with regard to jurisdictional claims in published maps and institutional affiliations. 